\title{
ANALYSIS OF U-TURNING BEHAVIOUR OF VEHICLES AT MID-BLOCK MEDIAN OPENING IN SIX LANE URBAN ROAD: A CASE STUDY
}

\author{
Vinay Kumar Sharma ${ }^{1}$, Satyajit Mondal ${ }^{2}$, Ankit Gupta ${ }^{3}$ \\ 1,2,3 Department of Civil Engineering, Indian Institute of Technology, Varanasi, India
}

Received 17 October 2017; accepted 8 April 2017

\begin{abstract}
The study considered the U- turning behaviour of vehicles at mid-block median opening in six lane divided urban road based on gap acceptance. Most of the median openings in India are uncontrolled and un-signalised. This study estimates critical gap or lag, accepted and rejected gaps, vehicle merging time and also a step forward to the modeling of critical gap. Six different sites of Jabalpur city (M.P) were selected for the purpose of field data collection. Data were collected in peak hours using video recording technique at the selected sections which are free from gradient, curves, on street parking, pedestrian movement and effect non-motorized vehicles. The entire traffic are categorised into five different classes such as 2-wheeler, 3-wheeler, Car/SUV, LCVs (light commercial vehicles) and HCVs (Heavy commercial vehicles). Three different methodologies namely traditional method, INAFOGA and Modified Raff's method are utilized for estimating critical gap. Regression technique is applied for modelling of critical gap using different independent variables for each motorized mode.
\end{abstract}

Keywords: accepted gap, critical gap, gap acceptance, merging behaviour, regression technique.

\section{Introduction}

Rapid urbanization increases number of vehicles significantly in the last two decades (Mondal et al., 2017). In most of the signalized intersection $U$ turning movements are not permitted to improve its operation condition through optimizing the conflicts point. Hence, some median openings are provided in such divided urban roads at an adequate interval particularly for U turn movements. Median openings are quite effective to access opposite traffic without creating any conflict with left-turns and crossing movements of that lane. While the turning operation is extremely complex due to the opposing traffic at median openings. Most of the median openings in India are uncontrolled. Thus, a U-turning vehicle needs to accept a time span or gap between the arrivals of successive vehicles on the through traffic of opposing lane to perform a safe turn. This is nothing but the gap acceptance phenomenon of the $U$ turning vehicles. Critical gap for U-turning vehicles is the time gap between two successive vehicles of the opposing road into which a U-turn vehicle may decide to merge. It is the minimum time interval that allows a vehicle to merge or cross

${ }^{1}$ Corresponding author: ksharma.civ14@itbhu.ac.in 
the opposing traffic safely. The length of critical gap is affecting the waiting time and merging time of the U-turn vehicle and also on the behaviour of following vehicles in the opposite traffic stream (Mahajan et al., 2015). Values of critical gaps are different for different vehicles and dependent on various parameters such as type of $U$ turn vehicle, several stream parameter of opposite lane and geometrical elements of the median. The U-turn operation sometime creates congestion in both the lanes as larger area is required and also increases vehicles delay, fuel consumption and accidental condition due to improper turning operation.

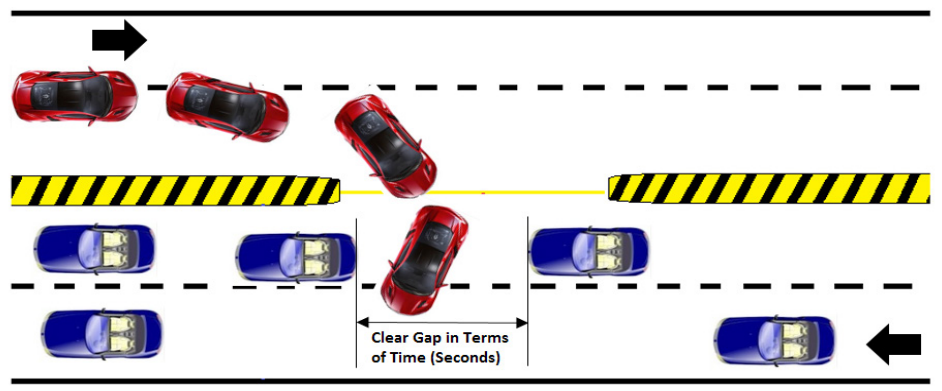

Fig. 1.

U-Turning Operation at Median Opening

U-turning region is defined as a hypothetical location where more automobiles try to share the equal space at the same time and thus create more conflict. Drivers of the U-turn vehicles select the lateral placing of vehicles based in the availability of the gaps in the existing lane while turning.

\section{Literature Review}

A number of studies were made on gap acceptance of vehicles since last few decades especially in case of median openings. Various methodologies and models were accepted related to critical gap though most of them were basically suited for the homogeneous traffic condition. Majority of studies usually considered the accepted and rejected gaps as the prime variables for evaluating critical gaps of vehicles. Hamed et al. (1997) studied gap acceptance at
T-intersection. They found the distribution of critical gap is influenced by driver socioeconomic characteristics, expect waiting time, time of day, and trip purpose. The mean critical gap is influenced by total opposing traffic flow, number of majorapproach lanes, presence of a median with a left-tum lane, manoeuvre type, speed of major road, and time of day. Jenjiwattanakul and Sano (2011) studied the effect of waiting time in gap acceptance at median opening. They observed that the waiting time of more than 30 seconds would frustrate the drivers to accept the significant smaller gap than the drivers facing smaller waiting time at the $90 \%$ confidence interval. Gurupackiam and Jones Jr. (2012) studied the psychology of the drivers for gap acceptance in congestion and found that drivers get more frustrated during non-recurring congestion that they accept smaller gaps and interaction between traffic 
streams affected field capacity. Brilon et al. (1999) recommended maximum likelihood procedure and Hewitt's method to determine the critical gap. The significant variation among critical gap values by estimation methods was observed as $12 \%$ to $38 \%$ by Ashalatha and Chandra (2011). The same factor was studied by Datta (2014) and revealed that the critical gap values obtained by INAFOGA method were $28-41 \%$ more than those obtained by Harder's method. Datta and Bhuyan (2014) found that the critical gap values obtained by INAFOGA were $18-31 \%$ more than those obtained by Probability Equilibrium method. Shihan and Mohammed (2009) done gap forcing simulation for U-turn and concluded that total delay, the average delay and average queue length per vehicle increased nonlinearly with increase in flow levels.

The best method of capacity estimation modified random platoon Tanner's formula first recommended by Aldian and Taylor (2001). Liu et al. (2008) suggested that vehicles making $U$-turns at median openings with wide medians have larger potential capacity than those making U-turns at median openings with narrow medians. Mohammed (2008) made capacity and average total delay models for U-turn movements at median openings and found that turning behaviour of vehicles significantly influenced by the conflicting traffic flow. Sugiarto et al. (2012) suggested that by adding a $50 \mathrm{~m}$ pocket lane would improve the existing situation by reducing the delay up to $69 \%$, increasing speed up to $39 \%$ and improving capacity up to $11 \%$.
Jenjiwattanakul et al. (2013) observed that the influential level of conflicting traffic volume on conflicting capacity decreased when the U-turn traffic volume increased. Effect of speed of major stream vehicles on the critical gap values of turning vehicles of minor stream was studied by Abhigna et al. (2015). They observed that the two wheelers are more aggressive vehicle type which will increase in the delay for major stream vehicle and reduces critical gap value with decrease in speed of the major stream vehicles.

\section{Problem Statement}

The movement of $U$ turn vehicle at median openings significantly affects the characteristics of traffic stream in both the lanes. In most of the median opening regions U-turn vehicles create more congestion due to its larger area requirement while turning and also increases accidental scenario due to the high speed traffic in the opposite lane. Thus the turning regions become an accident prone area. The problems tackled by drivers at the median openings enhance the interest to study the concept of merging behaviour of U-turn drivers at median openings. Therefore the study was considered with the following objectives:

- To evaluate the effect of lag, accepted gap, rejected gap and merging time on critical gap of $U$ turning vehicles;

- To estimate and model the critical gap of different $U$ turning vehicles at uncontrolled median opening under mix traffic condition. 


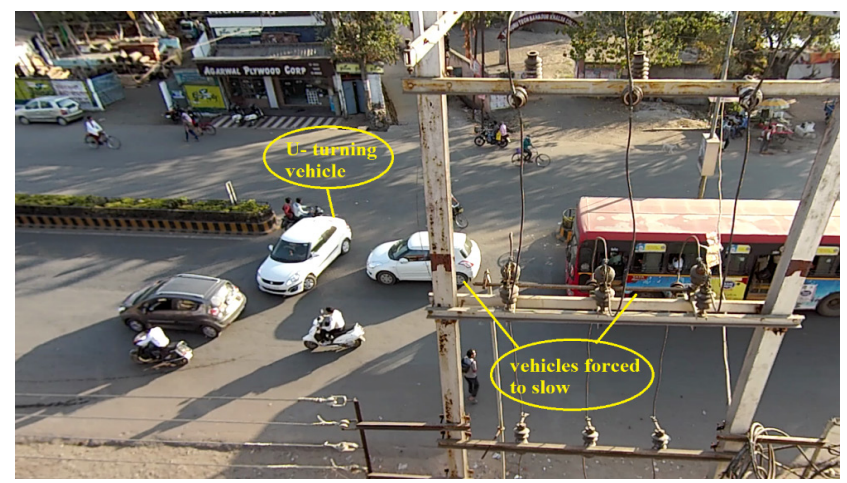

Fig. 2.

Snapshot of Video State

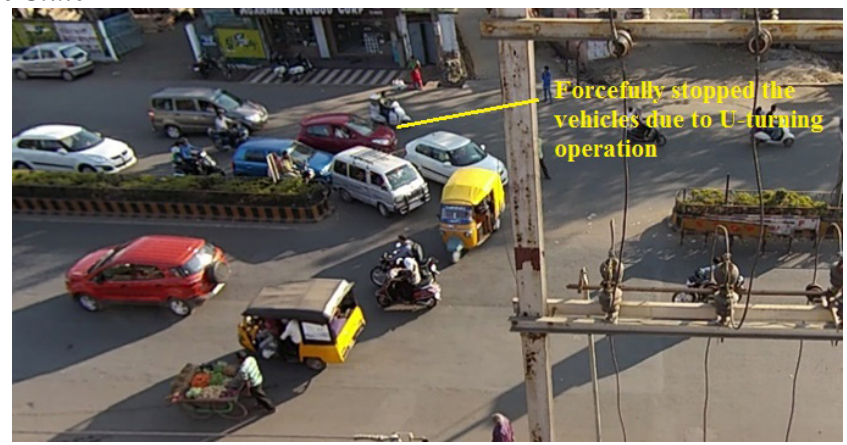

Fig. 3.

Snapshot of Video State

\section{Research Methodology}

The estimation of critical gap is a key parameter for analysing and designing a median opening. It is very difficult to measure the critical gap directly from the field. However, accepted and rejected gaps of $U$ turning vehicles can only be estimated directly from the field. The critical gap is solely associated with the accepted and rejected gap and can be estimated from those data using different methods. In these study three different methodologies namely Traditional method, Influence area for gap acceptance (INAFOGA) method and modified Raff's method were utilized for estimation of critical gap.

\section{Study Area and Data Collection}

\subsection{Selection of Study Area}

Mid-block median openings on six-lane divided urban roads were considered. All the selected sections were considered based on various criteria such as it should be free from gradient, curves, on street parking, pedestrian movement and effect non-motorized vehicles. The effect of speed for U-turning vehicles was also neglected. Total six median openings from Jabalpur city belongs to the state of Madhya Pradesh, India were taken. Initially it was observed that, percentage of vehicle makes U-turn at median openings was proportionately 
high as the distance of the opening increases from nearest intersection. Hence a $200 \mathrm{~m}$ $-250 \mathrm{~m}$ distance was considered behind the selection of each median opening from its nearest intersection. The details of the study sections are shown in the table 1 .

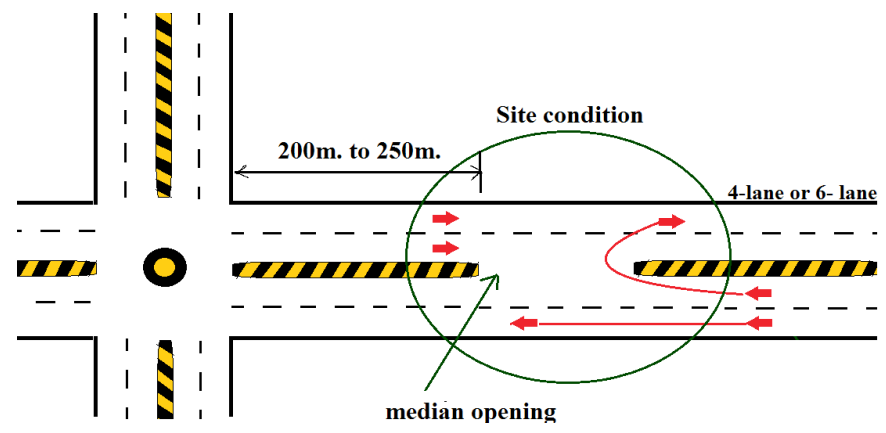

Fig. 4.

Layout of Site Condition

Table 1

Detail of the Selected Study Sections

\begin{tabular}{|c|c|c|c|c|c|}
\hline Section & City & Type of Carriageway & $\mathrm{a}^{*}(\mathbf{m})$. & $\mathbf{b}^{* *}(\mathbf{m})$. & $\mathrm{c}^{* * *}(\mathrm{~m})$. \\
\hline 1 & \multirow{6}{*}{ Jabalpur (M.P) } & \multirow{6}{*}{6 Lane } & 10.90 & 1.65 & 12.32 \\
\hline 2 & & & 18.75 & 1.65 & 12.80 \\
\hline 3 & & & 11.20 & 1.65 & 10.80 \\
\hline 4 & & & 10.90 & 1.65 & 10.50 \\
\hline 5 & & & 5.10 & 1.65 & 12.10 \\
\hline 6 & & & 4.90 & 1.65 & 12.85 \\
\hline
\end{tabular}

$\mathrm{a}^{*}=$ Width of Median opening (m)

$\mathrm{b}^{* *}=$ Width of Median (m)

$c^{* * *}=$ Width of carriageway (One Direction) (m)

\subsection{Data Collection}

Data for this study were collected at six selected median openings in urban areas using video recording technique. The recording was done from top of a building by fixing a camera on a tripod stand so that the entire median and its vehicular movement can be captured shown in figure 5. Field data were collected during peak hours of morning (9:00 am - 11:00 am), and evening $(4: 00 \mathrm{pm}-6: 00 \mathrm{pm})$ in between December, 2015 to February, 2016 on typical weekdays. 


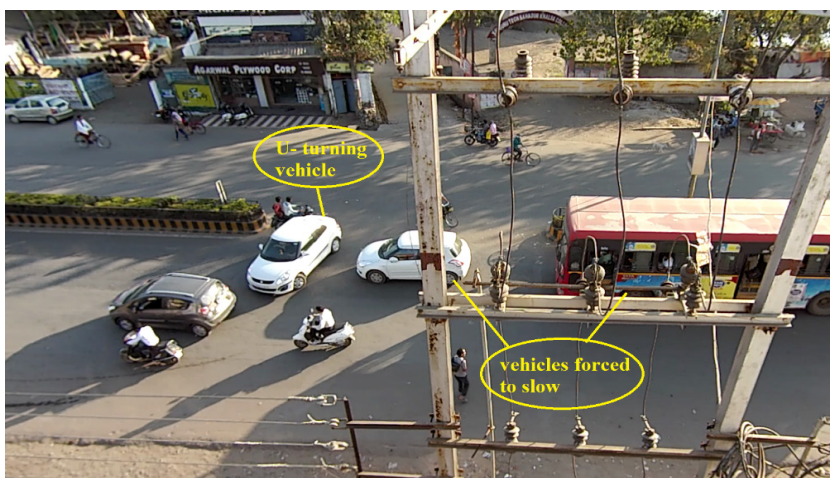

Fig. 5.

Snapshot of Video State

\section{Data Extraction}

The collected field data at the selected study sections were extracted to obtain different traffic stream parameters. The traffic flow condition is heterogeneous at the study sections, consisting of different categories of vehicles. Even with the same category of vehicle there are several models observed in the study sites. So, all vehicles in the traffic stream were grouped and divided into several categories such as Two Wheelers, Three Wheelers, Car/SUV, Light Commercial Vehicles and Heavy Commercial Vehicles (Bus, Truck, Tractor without trolley, Traveller etc.). Essential data were extracted from the recorded video and processed them for modelling critical gap for individual vehicles.

\subsection{Traffic Characteristics}

Initially the vehicles count in through traffic and $U$ turning region were extracted by playing the recorded video in a work station. Table 3 shows the number of vehicles in equivalent value of passenger car in through and U-turning traffic stream. The conversion is done by adopting the PCU values given by IRC-86:1983 shown in table 2 . The composition of individual vehicle in those two traffic stream were also estimated shown in Table 3 and 4.

Table 2

Standard PCUs Factors as per IRC-86:1983

\begin{tabular}{|l|l|}
\hline Vehicle Category & PCU Factor \\
\hline 2W (Motorised) & 0.5 \\
\hline Car, 3W, SUV, LCV, & 1.0 \\
\hline HCV (Bus, Truck etc.) & 3.0 \\
\hline
\end{tabular}




\section{Table 3}

Details of Traffic Characteristics at the Selected Sections

\begin{tabular}{|l|l|l|l|}
\hline Section & $\begin{array}{l}\text { Volume of Through Traffic } \\
\text { (PCU/hr/Lane) }\end{array}$ & $\begin{array}{l}\text { Proportion of U-Turning } \\
\text { Traffic (PCU/hr/Lane) }\end{array}$ & $\begin{array}{l}\text { Proportion of U-Turning } \\
\text { Traffic (\%) }\end{array}$ \\
\hline 1 & 1746 & 387 & 22.14 \\
\hline 2 & 1359 & 85 & 6.22 \\
\hline 3 & 1580 & 114 & 7.18 \\
\hline 4 & 1638 & 67 & 4.09 \\
\hline 5 & 1873 & 23 & 1.23 \\
\hline 6 & 2103 & 19 & 0.90 \\
\hline
\end{tabular}

Table 4

Traffic Composition of Different Motorised Mode at Selected Study Sections

\begin{tabular}{|c|c|c|c|c|c|c|c|c|c|c|c|c|c|}
\hline \multirow[b]{2}{*}{ Site } & \multicolumn{3}{|c|}{ Traffic Volume (veh/hr) } & \multicolumn{5}{|c|}{$\begin{array}{l}\text { Composition of Through Traffic } \\
(\%)\end{array}$} & \multicolumn{5}{|c|}{$\begin{array}{l}\text { Composition of U-Turning traffic } \\
(\%)\end{array}$} \\
\hline & Total & $\begin{array}{l}\text { Through } \\
\text { Traffic } \\
\end{array}$ & $\begin{array}{l}\text { U-Turning } \\
\text { Traffic }\end{array}$ & 2-W & $3-W$ & $\begin{array}{l}\text { CAR/ } \\
\text { SUV }\end{array}$ & LCV & $\mathrm{HCV}$ & 2-W & $3-W$ & $\begin{array}{l}\text { CAR/ } \\
\text { SUV }\end{array}$ & LCV & $\mathrm{HCV}$ \\
\hline 1 & 3215 & 2685 & 530 & 62.9 & 5.8 & 12.6 & 1.1 & 1.1 & 9.8 & 2.6 & 3.4 & 0.4 & 0.2 \\
\hline 2 & 1859 & 1733 & 126 & 55.5 & 15.3 & 16.7 & 1.9 & 3.8 & 4.9 & 0.7 & 0.8 & 0.3 & 0.1 \\
\hline 3 & 2257 & 2103 & 154 & 60.0 & 12.6 & 13.7 & 1.6 & 3.1 & 4.0 & 0.6 & 0.6 & 0.3 & 0.1 \\
\hline 4 & 2469 & 2370 & 99 & 70.0 & 9.0 & 11.9 & 2.4 & 2.7 & 2.9 & 0.2 & 0.6 & 0.2 & 0.1 \\
\hline 5 & 2579 & 2550 & 29 & 56.2 & 23.3 & 15.9 & 2.6 & 0.9 & 0.5 & 0.3 & 0.2 & 0.1 & 0.0 \\
\hline 6 & 2885 & 2861 & 24 & 56.2 & 21.9 & 17.0 & 3.2 & 0.9 & 0.3 & 0.2 & 0.2 & 0.1 & 0.0 \\
\hline
\end{tabular}

\subsection{Characteristics of Merging Vehicles}

The INfluence Area FOr Gap Acceptance (INAFOGA) for every U-turning vehicle was drawn using callouts in the Camtasia. Figure 6 represents a rectangular area bounded by the Red, violet and yellow lines where yellow line represents the stop line of the U-turn vehicle after approaching the median opening while the red and violet lines are the upstream and downstream ends of INAFOGA. The violet line is drawn, from where the U-turning vehicles finally merge straight with the conflicting traffic in such a way that rear bumper should touch the line. Table 5 shows the mean value of gap variables to evaluate critical gap for individual vehicle type at six lane divided roads.

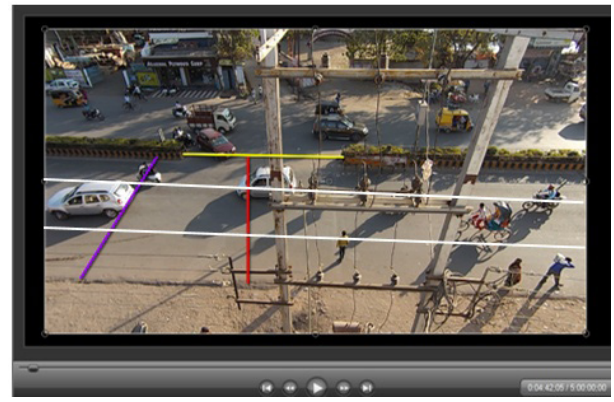

Fig. 6.

Schematic Diagram of Influence Area for Gap acceptance on a 6-Lane Divided Carriageway in Camtasia 8.6. 


\section{Table 5}

Details of Gap Variables of Individual Vehicle Type

\begin{tabular}{|l|l|l|l|l|l|}
\hline $\begin{array}{l}\text { Type of } \\
\text { Carriageway }\end{array}$ & Vehicle Type & Lag, secs & Accepted Gaps, secs & Rejected Gaps, secs & Merging Time, secs \\
\hline \multirow{5}{*}{6} & TW & 1.18 & 3.64 & 1.33 & 2.70 \\
\cline { 2 - 6 } & $3 \mathrm{~W}$ & 1.44 & 2.80 & 1.78 & 3.87 \\
\cline { 2 - 6 } & Car/SUV & 1.45 & 4.14 & 1.99 & 3.27 \\
\cline { 2 - 6 } & LCV & 1.20 & 4.46 & 1.77 & 3.62 \\
\cline { 2 - 6 } & HCV & 2.79 & 4.15 & 3.39 & 3.59 \\
\hline
\end{tabular}

\section{Analysis and Results}

\subsection{Estimation of Critical Gap}

Critical gap for each vehicle type was estimated using three different methodologies namely traditional method, INAFOGA method and modified Raff's method. The frequency distribution based on the different aspects were plotted using the above three methods where the intersection point gives the critical gap value for a certain motorized mode. Figure 7 shows the frequency distribution plot for car/SUV on six lane divided road using the three different methods. The values of critical gap of other motorized modes are given in table 6 for each study section.

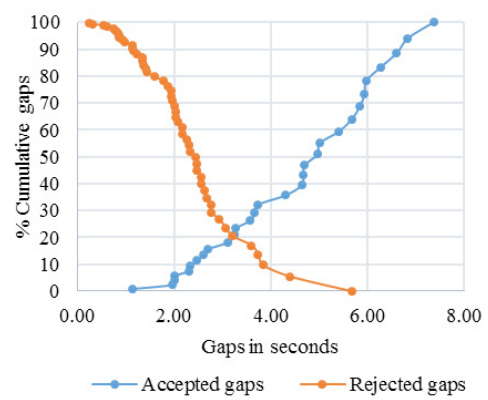

(a)

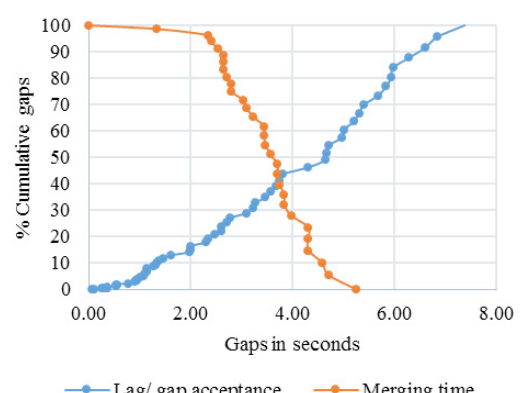

(b) 


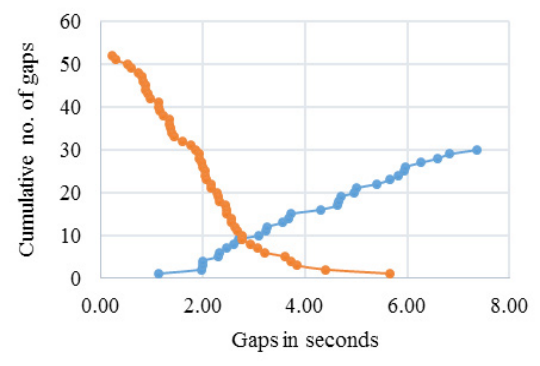

$\longrightarrow$ No. of accepted gaps $\longrightarrow$ No. of rejected gaps

(c)

Fig. 7.

Frequency Distribution Plot for Car/SUV for Six Lane Road Using (a) Traditional Method, (b) INAFOGA Method and (c) Modified Raff's Method

Table 6

Critical Gap Values of Different U-Turn Vehicles

\begin{tabular}{|c|c|c|c|c|}
\hline \multirow[t]{2}{*}{ Section } & \multirow[t]{2}{*}{ Vehicle Mode } & \multicolumn{3}{|c|}{$\begin{array}{l}\text { Critical gap(s) for U-Turns at Median Opening by Existing } \\
\text { Methods (secs) }\end{array}$} \\
\hline & & Traditional & INAFOGA & Modified Raff \\
\hline \multirow{5}{*}{$\begin{array}{l}\text { 1.Khalsa College } \\
\text { (M.P.) }\end{array}$} & $2 \mathrm{~W}$ & 2.62 & 2.62 & 2.47 \\
\hline & $3 \mathrm{~W}$ & 2.63 & 3.00 & 2.23 \\
\hline & Car/ SUV & 3.12 & 3.71 & 2.75 \\
\hline & $\mathrm{LCV}$ & 3.11 & 3.7 & 3.16 \\
\hline & $\mathrm{HCV}$ & 4.89 & 3.96 & 3.17 \\
\hline \multirow{5}{*}{$\begin{array}{l}\text { 2.Tripuri Chowk } \\
\text { (M.P.) }\end{array}$} & $2 \mathrm{~W}$ & 2.68 & 2.62 & 2.46 \\
\hline & $3 \mathrm{~W}$ & 2.62 & 3.04 & 2.24 \\
\hline & Car/SUV & 3.18 & 3.79 & 2.82 \\
\hline & LCV & 4.01 & 3.91 & 3.78 \\
\hline & $\mathrm{HCV}$ & 4.98 & 4.79 & 4.26 \\
\hline \multirow{5}{*}{$\begin{array}{l}\text { 3.Medical Bus Stand } \\
\text { (M.P.) }\end{array}$} & $2 \mathrm{~W}$ & 2.71 & 2.63 & 2.48 \\
\hline & $3 \mathrm{~W}$ & 2.73 & 3.01 & 2.25 \\
\hline & Car/ SUV & 3.02 & 3.81 & 2.74 \\
\hline & LCV & 3.16 & 3.89 & 3.71 \\
\hline & $\mathrm{HCV}$ & 5.02 & 4.11 & 3.94 \\
\hline \multirow{5}{*}{$\begin{array}{l}\text { 4.Khalsa College } \\
\text { (M.P.) }\end{array}$} & $2 \mathrm{~W}$ & 2.82 & 2.55 & 1.96 \\
\hline & $3 \mathrm{~W}$ & 2.58 & 3.17 & 2.06 \\
\hline & Car/SUV & 3.16 & 3.63 & 2.65 \\
\hline & $\mathrm{LCV}$ & 3.05 & 3.86 & 3.14 \\
\hline & $\mathrm{HCV}$ & 3.98 & 3.86 & 3.18 \\
\hline \multirow{5}{*}{$\begin{array}{l}\text { 5.Medical College } \\
\text { (M.P.) }\end{array}$} & $2 W$ & 2.38 & 3.97 & 2.07 \\
\hline & $3 \mathrm{~W}$ & 2.8 & 3.53 & 2.69 \\
\hline & Car/SUV & 3.18 & 3.67 & 2.86 \\
\hline & LCV & 3.24 & 3.72 & 3.09 \\
\hline & $\mathrm{HCV}$ & - & - & - \\
\hline \multirow{5}{*}{$\begin{array}{l}\text { 6.Medical College } \\
\text { Opposite side (M.P.) }\end{array}$} & $2 \mathrm{~W}$ & 3.17 & 3.29 & 2.87 \\
\hline & $3 \mathrm{~W}$ & 2.82 & 3.51 & 2.73 \\
\hline & Car/ SUV & 5.2 & 4.08 & 5.86 \\
\hline & LCV & 4.31 & 3.56 & 3.21 \\
\hline & $\mathrm{HCV}$ & - & - & - \\
\hline
\end{tabular}




\subsection{Statistical Test for Significance of Variance Between Existing Methods}

Single factor ANOVA test was applied for comparing the means and also to find out the significant relations between various variables. The test was performed among the three different methods. Table 7 and 8 show the details of values after applying the ANOVA test.

Table 7

Descriptive Statistics of Critical Gap

\begin{tabular}{|l|l|l|l|l|}
\hline Groups & Count & Sum & Average & Variance \\
\hline Traditional & 36 & 129.39 & 3.59 & 1.60 \\
\hline INAFOGA & 36 & 136.35 & 3.79 & 0.62 \\
\hline Modified Raff & 36 & 118.36 & 3.29 & 1.75 \\
\hline
\end{tabular}

\section{Table 8}

Result of ANOVA Test

\begin{tabular}{|l|l|l|l|l|l|l|}
\hline ANOVA & P.S. & D.F. & M.S. & F & P-value & F critical \\
\hline Source of Variation & S.S. & 2.29 & 1.72 & 0.18 & 3.08 \\
\hline Between Groups & 4.57 & 2 & 2.29 & & \\
\hline Within Groups & 139.24 & 105 & 1.33 & & & \\
\hline Total & 143.82 & 107 & & & & \\
\hline
\end{tabular}

It is observed from above table that there is no significant difference among the three methods and the null hypothesis can be accepted. As the three methods are using different parameters for calculating critical gap so there may be a chance for significantly different from each other. A paired t-test was applied on each pair of two methods to check its difference from each other.

\section{Table 9}

Results of Paired T-Test Between Traditional and INAFOGA Methods

\begin{tabular}{|l|l|l|l|l|l|l|}
\hline Groups & Count & Mean & S.D. & S.E. & t & D.F. \\
\hline Traditional & 36 & 3.59 & 1.27 & & & \\
\hline INAFOGA & 36 & 3.79 & 0.79 & & & \\
\hline Difference & 36 & -0.19 & 0.96 & 0.16 & -1.21 & 35 \\
\hline T TEST & p-value & t-critical & lower & upper & significance difference \\
\hline \multicolumn{7}{|l|}{} \\
\hline One Tail & 0.12 & 1.69 & & & no \\
\hline Two Tail & 0.23 & 2.03 & -0.52 & 0.13 & no \\
\hline
\end{tabular}

\section{Table 10}

Results of Paired T-Test Between INAFOGA and Modified Raff's Methods

\begin{tabular}{|l|l|l|l|l|l|l|}
\hline Groups & Count & Mean & S.D. & S.E. & t & D.F. \\
\hline INAFOGA & 36 & 3.79 & 0.79 & & & \\
\hline Modified Raff & 36 & 3.29 & 1.32 & & & \\
\hline Difference & 36 & 0.50 & 0.94 & 0.16 & 3.21 & 35 \\
\hline T TEST & p-value & t-critical & lower & upper & significance difference \\
\hline \multicolumn{7}{|l|}{} \\
\hline One Tail & 0.001 & 1.690 & & & yes \\
\hline Two Tail & 0.003 & 2.030 & 0.183 & 0.816 & yes \\
\hline
\end{tabular}




\section{Table 11}

Results of Paired T-Test Between Traditional and Modified Raff's Methods

\begin{tabular}{|l|l|l|l|l|l|l|}
\hline Groups & Count & Mean & S.D. & S.E. & t & D.F. \\
\hline Traditional & 36 & 3.59 & 1.27 & & & \\
\hline Modified Raff & 36 & 3.29 & 1.32 & & & \\
\hline Difference & 36 & 0.31 & 0.66 & 0.11 & 2.81 & 35 \\
\hline T TEST & p-value & t-critical & lower & upper & significance difference \\
\hline \multicolumn{7}{|l|}{} \\
\hline One Tail & 0.004 & 1.690 & & & yes \\
\hline Two Tail & 0.008 & 2.030 & 0.085 & 0.528 & yes \\
\hline
\end{tabular}

Table 9, 10 and 11 show the results of the statistical paired t-test performed on each pair. The result implies that there is no significant difference between traditional and INAFOGA method as the $\mathrm{p}$ value is greater than 0.05 and the $t$ critical value is also greater than $t$ stat. But the results in table 10 and 11 show a significant difference between the concerned methods due to its lower $\mathrm{p}$ value and higher $\mathrm{t}$ stat value than $\mathrm{t}$ critical.

\subsection{Modelling of Critical Gap}

Modelling of critical gap was done by considering five different independent variables such as lag, accepted gap, rejected gap, merging time and conflicting traffic. One of the most useful tool regression technique was used to find the empirical relationships between the critical gap (dependent variable) and those five independent variables. A base model was first formed for every category of vehicles considering all five independent variables. Statistical t-test was applied to check the significant differences between those independent variables considering in the base model. The variables whose probability value is less than the significance level (5\%) were only considered in final modelling of critical gap for each category of vehicles.

\section{Table 12}

Critical Gap Modelling for Each Motorised Mode

\begin{tabular}{|l|l|l|l|l|}
\hline Vehicle type & Variables considered & p value & Critical gap model & $\mathbf{R}^{2}$ \\
\hline Two Wheelers & Merging time, Accepted gap & $0.005,0.010$ & $\mathrm{~T}_{c}=-0.133+0.0595 \mathrm{~T}_{\mathrm{mg}}+0.416 \mathrm{~T}_{\mathrm{a}}$ & 0.922 \\
\hline Three Wheelers & Merging time, Accepted gap & $0.002,0.001$ & $\mathrm{~T}_{\mathrm{c}}=0.113+0.337 \mathrm{~T}_{\mathrm{mg}}+0.554 \mathrm{~T}_{\mathrm{a}}$ & 0.994 \\
\hline Car/ SUVs & Accepted gap & 0.001 & $\mathrm{~T}_{c}=0.199+0.817 \mathrm{~T}_{\mathrm{a}}$ & 0.829 \\
\hline LCVs & Merging time & 0.027 & $\mathrm{~T}_{\mathrm{c}}=1.256+0.620 \mathrm{~T}_{\mathrm{mg}}$ & 0.525 \\
\hline HCVs & Accepted gap & 0.005 & $\mathrm{~T}_{\mathrm{c}}=1.822+0.492 \mathrm{~T}_{\mathrm{a}}$ & 0.827 \\
\hline Common mode & Merging time, Accepted gap & $0.0004,0.0001$ & $\mathrm{~T}_{c}=0.106+0.385 \mathrm{~T}_{\mathrm{mg}}+0.491 \mathrm{~T}_{\mathrm{a}}$ & 0.816 \\
\hline
\end{tabular}

$\mathrm{T}_{\mathrm{c}}$ : Critical gap

$\mathrm{T}_{\mathrm{mg}}$ : Merging time of vehicle

$\mathrm{T}_{\mathrm{a}}$ : Accepted gap 
Table 12 shows the descriptive statistics of the independent variables considered in final modelling along with the proposed models for each vehicle type. Five individual models were proposed for each vehicle class and a generalized model fit to each vehicle class was also developed. It was observed that all the proposed models were having high $\mathrm{R}^{2}$ value indicates the high implication level of each model except the model proposed for LCVs.

\section{Conclusions}

This paper estimates critical gap of individual $U$ turning vehicle at six different median openings on six lane divided road under mixed traffic condition. Data were collected during peak hours on each selected section. Three different methodologies namely traditional method, INAFOGA and Modified Raff's method were applied to estimate the critical gap. Values of critical gaps obtained by INAFOGA method are about $5.93 \%$ higher than traditional method and about $16.38 \%$ higher than Modified Raff's method. The drivers of two wheelers take the smaller available critical gaps, according to their smaller dimensions. While HCV takes the higher critical value due its larger size and less manoeuvrability characteristics. Five different independent variables were considered for modelling of critical gap. Regression technique was used to find the empirical relationships between the critical gap and those independent variables whose probability value is less than the significance level (5\%). Each model contains high coefficient of determination $\left(\mathrm{R}^{2}\right)$ with low additive constant value indicate its significance level. A model was proposed considering all motorised mode as a common mode where the critical gap depends on merging time and accepted gaps with high coefficient of determination and low value of coefficients.

\section{Limitations}

The application of this study is to design of signal cycle length for the U-turning traffic and through traffic of opposite lanes to make controlled median opening for safe and efficient vehicular movement through the median openings. This study investigates gap acceptance characteristics of different categories of vehicles and has not looked into the effect of speed on the gap acceptance of a U-turning vehicle. The speed of U-turning vehicle certainly influences the placement of U-turning vehicles which is proposed to be investigated in the future study. The safety aspect associated with the U-turning vehicles at the median openings is also proposed to be looked upon in future work. In the present study, critical gap and modelling of critical gap are determined only for six lane divided urban roads. This study could be extended for the other types of divided roads.

\section{References}

Abhigna, D.; Brahmankar, D.P.; Shankar, R. 2015. Multi Vehicle-Type Gap Acceptance and Capacity Analysis in Uncontrolled Urban Intersections. In Proceedings of the National Conference on Recent Advances in Traffic Engineering, RATE- 2015, SVNIT.

Aldian, A.; Taylor, M.A.P. 2001. Selecting Priority Junction Traffic Models to Determine U- Turn Capacity at Median Opening. In Proceedings of the Eastern Asia Society for Transportation Studies, 3(2): 101-113. 
Ashalatha, R.; Chandra, S. 2011. Critical Gap through Clearing Behaviour of Drivers at Un-signalised Intersections, KSCE Journal of Civil Engineering 15(8): 1427-1434.

Brilon, W.; Koenig, R.; Troutbeck, R.J. 1999. Useful estimation procedures for critical gaps, Transportation Research Part A: Policy and Practice 33(3): 161-186.

Datta, S. 2014. Modelling Critical Gaps for U-Turn Vehicles at Median Openings Under Indian Mixed Traffic Conditions. Department of Civil Engineering, National Institute of Technology Rourkela. 111 p.

Datta, S.; Bhuyan, P.K. 2014. Which Method Is Appropriate-INAFOGA or Probability Equilibrium For Critical Gap Estimation Of U-Turn Vehicles At Median Openings In Urban Indian Context?. In Proceedings of the International Conference on Advances In Engineering And Technology - ICAET-2014, 459-465.

Gurupackiam, S.; Jones Jr., S.L. 2012. Empirical Study of Accepted Gap and Lane Change Duration within Arterial Traffic under Recurrent and Non-Recurrent Congestion, International Journal for Traffic and Transport Engineering 2(4): 306-322.

Hamed, M.M.; Easa, S.; Batayneh, R.R. 1997. Disaggregate Gap-Acceptance Model for Un-Signalized T-Intersections, Journal of Transportation engineering 1(123): 36-42.

IRC: 86-1983. Geometric Design Standards for Urban Roads in Plains. Indian Roads Congress, New Delhi. 29 p.

Jenjiwattanakul, T; Sano, K. 2011. Effect of Waiting Time on the Gap Acceptance Behavior of U-turning Vehicles at Midblock Median Openings, In Proceedings of the $9^{\text {th }}$ International Conference of Eastern Asia Society for Transportation Studies, 314-314.
Jenjiwattanakul, T.; Sano, K.; Nishiuchi, H. 2013. Capacity of U- Turn Junction at Midblock Median Opening on Urban Arterial Based on Balancing Volume to Capacity Ratio, In Proceedings of National Conference on Recent Advances in Traffic Engineering, RATE- 2015, SVNIT.

Liu, P.; Lu, J.J.; Fengxuan, H.; Sokolow, G. 2008. Capacity of U-Turn Movement at Median Openings on Multilane Highways, Journal of Transportation Engineering 134(4): 147-154.

Mahajan, K.; Gupta, A.; Ohri, A. 2015. A Critical Review on Capacity Estimation Approaches for Mixed Traffic Conditions in Developing Countries, In Proceedings of the $15^{\text {th }}$ PIARC World Road Conference, ID: IP570-Mahajan-E.

Mohammed, H. 2008. Model Development of U-Turn Capacity Using Simulation and Empirical Approaches, In Proceedings of the Stregional Conference of Engineering Science, 11(1): 189-193.

Mondal, S.; Chakraborty, S.; Roy, S. K; Gupta, A. 2017. Estimation of Passenger Car Unit for Heterogeneous Traffic Stream of Urban Arterial: Case Study of Kolkata, Transportation Letters: The International Journal of Transportation Research DOI: 10.1080/19427867.2017.1293313.

Shihan, H.; Mohammed, H.K. 2009. Traffic System Studies at Median U-Turn in Baghdad City Employing U-Sim Model, Journal of Engineering and Development 13(1): 1813-7822.

Sugiarto, S.; Limanoond, T; Nakatsuji, T. 2012. Dropped in Capacity and Traffic Speed of Urban Arterial: A Case Study at U-Turn Section in Aceh Province, Indonesia Aceh, International Journal of Science and Technology 1(3): 86-93. 